\title{
Towards smart(er) resilient cities. Evidences from Romanian urban areas
}

\author{
ALEXANDRU BĂNICA ${ }^{1,2}$, MIHAIL EVA ${ }^{1}$, EMA CORODESCU-ROȘCA ${ }^{1}$, \\ BOGDAN-CONSTANTIN IBĂNESCU ${ }^{3}$, ANA-MARIA OPRIA ${ }^{1}$, \\ GABRIELA CARMEN PASCARIU ${ }^{3}$
}

1 Alexandru Ioan Cuza University of Iaşi, Faculty of Geography and Geology, Department of Geography, Iasi, Romania; e-mail: alexandru.banica@uaic.ro, mihail.eva@uaic.ro, ema.corodescu@gmail.com, opriaanamaria@gmail.com

2 Romanian Academy. Iași Branch, Romania

3 Alexandru Ioan Cuza University, Faculty of Law, Centre for European Studies, Iasi, Romania; e-mail: ibanescu.bogdan@uaic.ro, gcpas@uaic.ro

ABSTRACT The investment in communication technologies has become increasingly prominent in cities, as they face a considerable pressure to become "smarter". Connected technologies are able to collect and analyze data in real time, leading to predictive and adaptive decisions. However, being smart(er) does not necessary mean being more resilient; in fact, using sophisticated technologies may have some drawbacks that diminish the general resilience capacity of cities. The present paper aims to explore the relationship between resilience and smart city initiatives. The number of smart city projects is therefore firstly correlated with the resilience capacity (built on three dimensions: economic, socio-demographic, and environmental), then to the outcome resilience (calculated as the recovery following the recent economic crisis). The results show a clear connection between the most socially resilient cities, the share of employment in tertiary activities, and the implementation of smart city projects.

KEY WORDS smart cities - smart initiatives - resilience capacity - resistance - recoverability resilience performance

BĂNICĂ, A., EVA, M., CORODESCU-ROȘCA, E., IBĂNESCU, B.C., OPRIA, A.M., PASCARIU, G.C. (2020): Towards smart(er) resilient cities. Evidences from Romanian urban areas. Geografie, 125, 4, 397-422.

https://doi.org/10.37040/geografie2020125040397

Received July 2019, accepted March 2020.

C Česká geografická společnost, z. s., 2020 


\section{Introduction}

The contemporary society is characterized by a constant trend of reinvention, innovation, and integration of information technology in all branches of activity. This is constantly pushing the modern cities to adapt to the successive challenges through smart initiatives (Caragliu, Del Bo 2019). Given the rapid pace of transformation, as well as the growing interconnectivity of sectors, the changes that cities endure can no longer be considered isolated phenomena; on the contrary, they appear to be present in all economic sectors. The changes inevitably lead to a greater diversity of issues that urban society faces and implicitly to a necessity to identify those factors, elements or solutions that can build and sustain an urban equilibrium in face of noticeable constant change. Therefore, modern cities have to constantly invest in increasing their ICT integration in addition to maintaining an internal equilibrium and awareness regarding potential future shocks. While the first ability is to define the urban "smartness" and gravitates around the modern concept of smart city, the later largely refers to the notion of resilience. Urban resilience can be defined as the "ability of an urban system-and all its constituent socio-ecological and socio-technical networks across temporal and spatial scales-to maintain or rapidly return to desired functions in the face of a disturbance, to adapt to change and to quickly transform systems that limit current or future adaptive capacity" (Meerow, Newell, Stults 2016, p. 45).

It is, therefore, necessary to investigate to which extent urban systems with a high level of resilience are geared towards integrating smart initiatives into their development strategies. Thus, the study of urban settlements resilience and, in particular, of the development directions they focused on after a shock can highlight the importance of smart initiatives in increasing or consolidating the urban resilience performance. In other words, have the resilient cities considered that investing in smart initiatives would contribute to increased performance in the face of future shocks? This is one of the questions that contemporary studies should respond to in order to determine the future development directions that less-performing urban systems could focus on. In this way, taking over and adapting successful models to other territorial realities will undoubtedly contribute to superior performance and adaptability against forthcoming disturbing events.

The recent literature includes a wide range of new city discourses including a multitude of concepts such as "smart", "intelligent", "innovative", "wired", "digital", "creative", etc., which are often based on the relation between technologicalinformational transformations and economic, political and socio-cultural change (Hollands 2008, Cocchia 2014, Thompson 2016, Kourtit 2019). Despite the morphological diversity, the above-mentioned concepts are often representing variations of the same central idea of smart city. For Caragliu, Del Bo and Nijkamp (2011) a city is smart if investments in human and social capital, respectively in traditional 
and modern communication infrastructure contribute significantly to sustainable economic growth and increase in the quality of life, while wisely managing the natural resources through participatory governance. In fact, a city becomes smart when targeting long-term productivity, inclusivity, and resiliency (Puentes, Tomer 2014), therefore addressing meta-issues such as climate change, urbanisation, citizen engagement and resource efficiency (Taylor Buck, While 2017). Smart cities encompass modern urban production factors in an integrative framework by effectively using ICTs, social and environmental capitals (Kourtit, Nijkamp 2012). The smart city concept has a high relevance for the resilience and the long-term sustainability of cities as it might contribute to a higher quality of life not just by promoting more efficient urban operation and services, but also by increasing environmental protection (lowering pollution and $\mathrm{CO}_{2}$ emissions, increasing air and water quality, sustaining green areas and balanced landscapes), urban competitiveness, accessibility, mobility, and liveability (by tackling issues related to health care, working conditions, safety and cost of living) (Romão et al. 2018).

Recent studies identified a close connection between city smartness and the equally essential urban feature known as resilience (Galderisi 2018; Li, Chen, Luna-Reyes 2017; Falco 2015; Viitanen, Kingston 2014). Urban resilience is usually defined as the competence of cities and metropolitan areas to respond, recover, cope, adapt and even develop when facing an unexpected, sudden perturbation, or stressor (Bănică, Muntele 2013, 2015). However, the resilience of an urban area does not exclude other features such as creativity or competitiveness. A resilient city is also a creative city, able to reinvent a new equilibrium against destabilizing external pressure while multiplying the potential of people to build new opportunities/alternatives (Baycan, Fusco Girard, Nijkamp 2011). Two different, yet accepted, approaches of resilience emerged during the last decade:

a) resilience capacity - a resilience based on process, which is not focused on a certain disaster, but on the ability to resist shocks as "some (...) [units] are structurally more prepared than others, and have greater capacity to bounce back in the wake of a stress" (Foster 2011)

b) resilience performance - a resilience based on outcome resilience i.e. response to past risk events or threats compared to a prior reference status (Bristow, Healy 2018).

Both notions of "smart" and "resilient" define cities aiming at building capabilities in order to prevent or deal with acute shocks and chronic stress by using a broad range of technologies. Meanwhile, those cities can also be defined as inclusive, given their ability to enable all stakeholders to participate in the settling and execution of policies and their investment in the development of human and social capital through education-based policies, sharing, and targeting a better life quality (Papa et al. 2015; Komninos et al. 2018). 
Smart initiatives should, in theory, allow cities to become more liveable and resilient and, hence, capable to respond more efficiently to different threats (Papa et al. 2015). Therefore, a smart city might include characteristics that would also provide resilience to the urban area. The main goals of smart strategies are intrinsically related to resilience factors such as adaptability, flexibility, and anticipation (i.e. readiness to adapt to unforeseen situations), connectivity and networking (i.e. connecting more effectively all urban components), diversity and integration (the highly diverse natural, human, economic, and institutional resources have to be brought together), collaboration and participation (of all stakeholders), awareness, creativity and learning capacity (urban management that addresses strengths and weaknesses while extending and preserving knowledge from new situations), monitoring and ensuring knowledge (i.e. observing, gathering reliable data and protecting the system from failure; Viitanen, Kingston 2014; Falco 2015; Papa et al. 2015; Galderisi, 2018). Becoming smart is not a destination, nor an end in itself, but rather an on-going process, with many stages, a journey of continuous improvement that is able to make urban areas more liveable and more resilient, therefore more capable to respond faster and effectively to both internal and external challenges (Ahuja 2016, Vaidyanathan 2016).

A smart strategy can mean different things to different cities (Hollands 2008), and it highly depends on the local context, as an activity that is considered to be smart in the case of one city could not be as such in the case of another city. An action is more suitable, more adapted, or more effective in one context compared to another. Nevertheless, there are some common actions that are generally considered as a part of the smart city concept. The literature identifies six domains of smart city actions: economy, mobility, environment, people, living, and governance, each comprising a multitude of actions that can be fulfilled (Albino, Berardi, Dangelico 2015; Monzon 2015; Lombardi et al. 2012).

However, there are still controversies related to these concepts. Both "smart" and "resilience" concepts are criticized for being catch-all concepts, often-used, yet imprecisely defined, while in practice they are sometimes exclusive or fail to address the real needs of the cities. Regarding resilience, some scholars argue that there is little substance beyond the theoretical developments. Consistent drawbacks can be observed as different conceptualisations (from engineering to ecological and economic views) can create a certain theoretical confusion (Nunes, Tome, Pinheiro 2019). Urban resilience meets the need of cities to adapt to new challenges (for e.g. climate change) but it is usually just an integrative metaphor (Pickett, Cadenasso, Grove 2004; Pendall, Foster, Cowell 2009), or a general framework (Ahern 2011), while there are only a few successful attempts to transform it in an integrated tool (Sharifi, Yamagata 2017). Meanwhile, the smart city concept has a dominant practical, technology-oriented approach; however, it lacks the conceptual background. The technology is not a goal in itself, as the smart city 
strategies should be integrated within the existing urban infrastructure in order to be effective. A better conceptualisation of "urban smartness" would emphasize the role of connectivity, efficiency in resource management and a more sustainable urban metabolism.

Resilience concept became popular in CEE countries during the last decade as it is used in various scientific areas (psychology, engineering, ecology, geography, economy, urban planning etc.). In urban studies, resilience became a framework to discuss different emerging issues such as economic crisis and urban systems crisis (Drobniak 2014), functional challenges, urban sprawl, shrinking cities and adaptation to new urban configurations (Bănică, Istrate, Muntele 2017, Bănică, Muntele 2017), vulnerability and recovery from natural disasters in urban areas (Boștenaru Dan, Armas, Goretti 2014) etc. One can distinguish two different approaches of resilience in former communist countries: the "good resilience", i.e. the adaptation of cities to the new post-socialist context from social, economic, infrastructural and environmental points of view, but also a "bad resilience" which is a form of resistance to change by maintaining inherited obsolete, inefficient and even harmful elements and practices (Rufat 2012; Bănică, Muntele 2017).

In the same context of CEE countries, the emergence of smart city concept is more recent and responds to other (complementary) needs of the restructured systems. The capitals and the large cities benefited the most from urbanization and agglomeration economies. For second-tier cities the only chance to achieve agglomeration effects can be enabled by investing in effective infrastructure, facilities and capacities. In this context, the pragmatic smart city concept represented an upgrade to urban economies by giving the smaller cities the institutional/ administrative/economic framework to adopt new technologies and to develop as hubs. This would reduce territorial and social disparities within the urban systems of the CEE countries (Kollar, Bubbico, Arsalides 2018). Nevertheless, CEE cities are rarely taken into account in global rankings as the scale of their smart innovation is rather small (Kola-Bezka, Czupich, Ignasiak-Szulc 2016). In the light of this general framework, the present paper aims to examine the relation between urban resilience and smart city initiatives in medium and big Romanian cities (over 50,000 inhabitants). Two hypotheses are raised in this respect:

1. The first hypothesis assumes that the cities endowed with a higher resilience capacity have also shown a higher tendency to implement smart projects.

2. The second hypothesis considers that cities having displayed a higher resilience performance during and after the economic crisis (in terms of employment dynamics), were also able to develop more smart projects afterwards.

In order to test these hypotheses, three main operational objectives are defined: (1) Mapping the smart city initiatives; (2) Measuring resilience capacity and resilience performance for Romanian cities and (3) Assessing the relationship 
between smart city initiatives and resilience. This paper is structured as follows: after this introduction, the second section presents the methodology employed for each of the three objectives; the third section contains the results of our analysis, accompanied by discussions, while the final section presents the conclusions of our study and introduces some policy implications and further research directions.

\section{Methodology}

The paper focuses on exploring the statistical relationship between resilience and smart cities initiatives in medium and big Romanian cities, namely the cities over 50,000 inhabitants according to the latest estimations of Romanian Institute of Statistics. The medium and big cities were chosen for two main reasons: (1) most of the smart initiatives have been implemented there; (2) the population size of those territorial units makes possible the diffusion of innovation to larger scale.

Our research methodology is developed in three steps, corresponding to the three operational objectives defined in the previous section.

1. Firstly, the "smart" performance of cities is assessed based on smart initiatives implemented by Romanian cities between 2012 and 2018. Data included the entire list of smart projects, subsequently classified by the domains they cover.

2. Secondly, the resilience of cities was assessed using the two resilience dimensions (capacity and performance) established by the contemporary literature.

The resilience capacity was assessed using the Resilience Capacity Index (RCI), proposed by Kathryn Foster from Buffalo Regional Institute (New York) in 2011 (Foster 2011). To date, RCI is one of the most integrative indexes used for resilience capacity assessment. It is based on 12 indicators that positively influence the ability of a city or metropolitan area to recover from a stress, grouped into three categories regarding different dimensions of regional capacity: economic, socio-demographic and community connectivity. In order to assess the resilience capacity for Romanian cities, our study uses an adapted RCI built in 2013 to better emphasize the Romanian territorial realities (Bănică, Muntele 2013). The adapted index was named Spatial Resilience Capacity Index (SRCI) and it was aggregated using data from local level in 3 domains, each consisting of four indicators considered relevant to Romanian territory (Table 1):

- Economic resilience (Econ_Res), built on income equality, economic diversification, regional affordability and the index of enterprise/innovation.

1 For this study, the authors used the estimations provided by the Romanian Institute of Statistics regarding the resident population on 1st January 2018. 


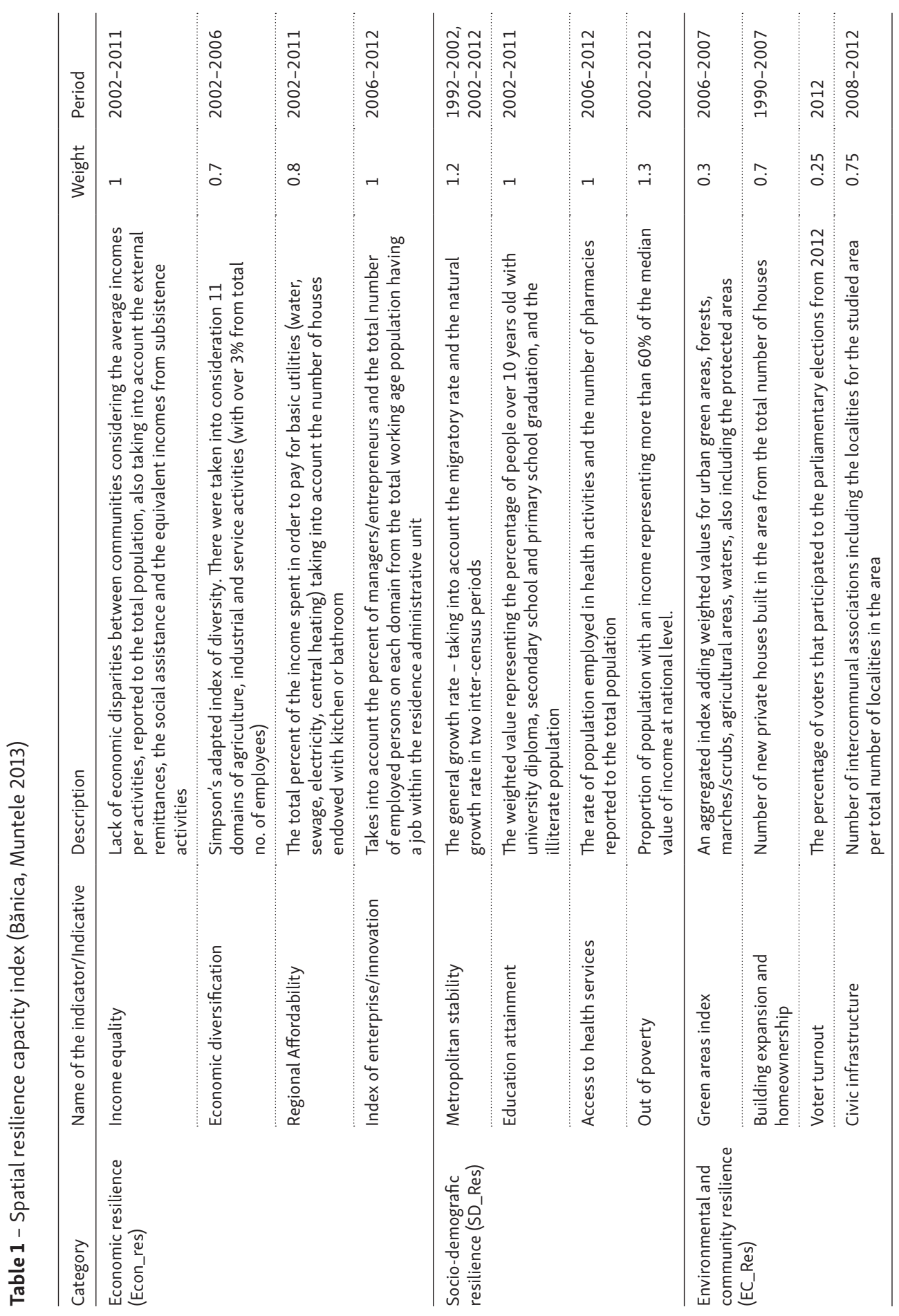


- Social-demographic resilience (SD_Res), seen as the readiness for situations of crisis and built on metropolitan stability, education attainment, access to health and the population outside the poverty risk.

- Environmental and community resilience (EC_Res), seen as the environmental endurance and the community's ability to associate and promote attachment to its own space, and built on green areas index, real estate expansion and home ownership, voter participation and civic infrastructure.

The 12 indicators were re-scaled using the minimum-maximum scheme. Then, the Principal Component Analysis (PCA) was applied to group the indicators by domains and to weigh them according to their relevance in the model (Bănică, Muntele 2013). The adapted indicator was calculated not only for medium cities and metropolitan areas, as defined by Romanian legislation and planning acts, but also for individual urban localities inside and outside the metropolitan area (Bănică, Muntele 2013, 2015). Therefore, the indicator displays flexibility in terms of application to different spatial scales corresponding to different urban policies.

The second dimension, resilience performance, was calculated for two different periods associated with the economic crisis: the resistance (2008-2011) and the recovery phase (2011-2016), by means of three proxies: change in the total employment, change in the secondary sector employment, and change in the tertiary sector employment. While the total employment is a very common indicator used in resilience studies (Fingleton, Garretsen, Martin 2012; Martin 2012; Sedita, De Noni, Pilotti 2017), the other two indicators are aimed at expressing the adaptive resilience to the economic crisis by means of economic restructuring.

For the estimation of the resilience performance by total employment, we used the methodology proposed by Martin (2012), which focuses on two dimensions of resilience: resistance and recoverability. They are calculated by comparing data on employment at the regional or city level to the national level, a value of 1 meaning a local behaviour similar to the national one, while values below or above this threshold mean better or worse performance of a given city compared to the national trend. The two indexes were calculated on the formula used by Östh, Reggiani and Nijkamp (2018):

$$
\text { Resist/Recov }=\frac{\Delta E_{r} / E_{r}-{ }^{\Delta E_{n} / E_{n}}}{\left|\Delta E_{n} / E_{n}\right|}
$$

Where $\Delta E_{r}$ - the change in regional employment during the given period (resistance or recovery); $E_{r}$ - regional employment at the beginning of the period; $\Delta E_{n}$ the change in national employment during the given period; $E_{n}$ - national employment at the beginning of the period. 
Table 2 - The categories of resilience performance in relation to resistance and recoverability (Martin et al. 2015)

\begin{tabular}{|c|c|c|c|}
\hline \multirow{4}{*}{ Resistance } & \multirow[t]{2}{*}{$\begin{array}{r}>0.0 \\
\\
0.0\end{array}$} & $\begin{array}{l}\text { Good resistance but weak } \\
\text { recoverability }\end{array}$ & $\begin{array}{l}\text { MOST RESILIENT } \\
\text { Good resistance and good } \\
\text { recoverability }\end{array}$ \\
\hline & & $\begin{array}{l}\text { Weak resistance and weak } \\
\text { recoverability } \\
\text { LEAST RESILIENT }\end{array}$ & $\begin{array}{l}\text { Weak resistance but good } \\
\text { recoverability }\end{array}$ \\
\hline & & $<0.0$ & $>0.0$ \\
\hline & & \multicolumn{2}{|c|}{ Recoverability } \\
\hline
\end{tabular}

The two measures of resistance and recoverability are centered on zero; therefore, positive values will mean a better resistance or recoverability than the national level, while negative values will correspond to less resistant or less recoverable cities or region. Consequently, four regional behaviors are possible, as combinations of resistance and recoverability (Table 2).

3. Thirdly, the correlations between our resilience capacity, resilience performance and smart city indicators were explored. Regression analysis was used to explore the strongest relationship identified: the relation between resilience performance (dynamics of employment in tertiary sector after the crisis) and SRCI. Finally, a typology was created by combining classes of cities according to their level of resilience and the number of smart initiatives implemented.

The data for the study is provided by the Romanian Institute of Statistics (demographic and social-economic indicators), the database on Romanian enterprises www.listafirme.ro (data on the number of employees in each economic sector) and the database on smart initiatives http://map.romaniansmartcity.ro/ (data on Romanian private and public smart city initiatives).

\section{Results}

\subsection{Mapping smart city initiatives in Romania}

The first outcomes of the current study are based on the exploratory analysis of the emergence of smart cities initiatives in Romania and consist of reports on the most prevalent domains addressed by these initiatives in Romania (in general and by city size) and, finally, on their spatial distribution.

Smart cities solutions are viewed as a novelty in many cities of the post-communist block (Sikora-Fernandez 2018). In Romania, as well as in other Central and East 
European countries, there is a lack of integrated and coordinated smart initiatives, as they mostly represent immediate solutions to urban issues and not a long-term development strategy (Borsekova, Nijkamp 2018). Romania still finds itself at the beginning of a long process, with a shy start and a relatively underdeveloped smart city sector (VEGACOMP 2018). Moreover, one can notice that the smart city concept was first introduced in CEE and Romania within the business environment, only afterwards being adopted by the public administration at city levels.

A report of the European Smart Cities Organization highlights that some of the most important Romanian cities are only in the first step of developing and implementing smart solutions (Batagan 2012); even some important metropolitan areas, such as Sibiu, Timișoara, and Craiova are ranked below EU average regarding smart city development (Rotuna et al. 2017). In fact, during the first phase, (1999-2012), only a few cities had initiatives in implementing smart solutions (Hunedoara, Iași, Piatra-Neamt, Sinaia). After 2012, other major cities with a high demographic, cultural, and industrial potential (Bucharest, Brașov, Sibiu, Timișoara, Craiova and Cluj-Napoca) followed this path in integrating smart solutions (Batagan 2012).

Nowadays, the leader of smart project implementation in Romania is the city Alba Iulia (82 implemented projects and 20 supplementary approved projects), followed by Timișoara (20), Hunedoara (20), Cluj-Napoca (13), Arad (12), Sibiu (9), Bucharest (8), and Iași (7).

Even though numerous projects fit in more than one domain, one can identify the main trends in each of the smart city key sectors. In Romania the most popular Smart City solutions include LED Street Lighting, smart parking, video surveillance and public Wi-Fi, but also traffic management systems, waste management and various sensors, such as environmental sensors used to monitor air quality (Fig. 1).

The most common projects by category could be assembled as follows:

- Smart Governance: online tax computing and tax payments, interaction with the city hall, public reporting for different situations (such as Civic Alert or My Braşov City), as well as the management of official authorization documents, notifications, certificates.

- Smart Living: public Wi-Fi in the cities' main points of interest, Wi-Fi in public transport, along with smart video surveillance and smart utilities, e.g. for power consumption measurement and management.

- Smart Economy: increasing energy efficiency, smart LED public lighting, smart metering and reporting systems for the utilities, smart poles providing Wi-Fi connectivity, electric car charging stations, outdoor digital display panels, air quality monitoring stations, video cameras for surveillance and outdoor parking sensors.

- Smart Mobility solutions aim at a more efficient and faster transport, in direct connection with the issues regarding traffic jams, pollution and quality of urban public transport. Most of the projects concern the optimization of the 


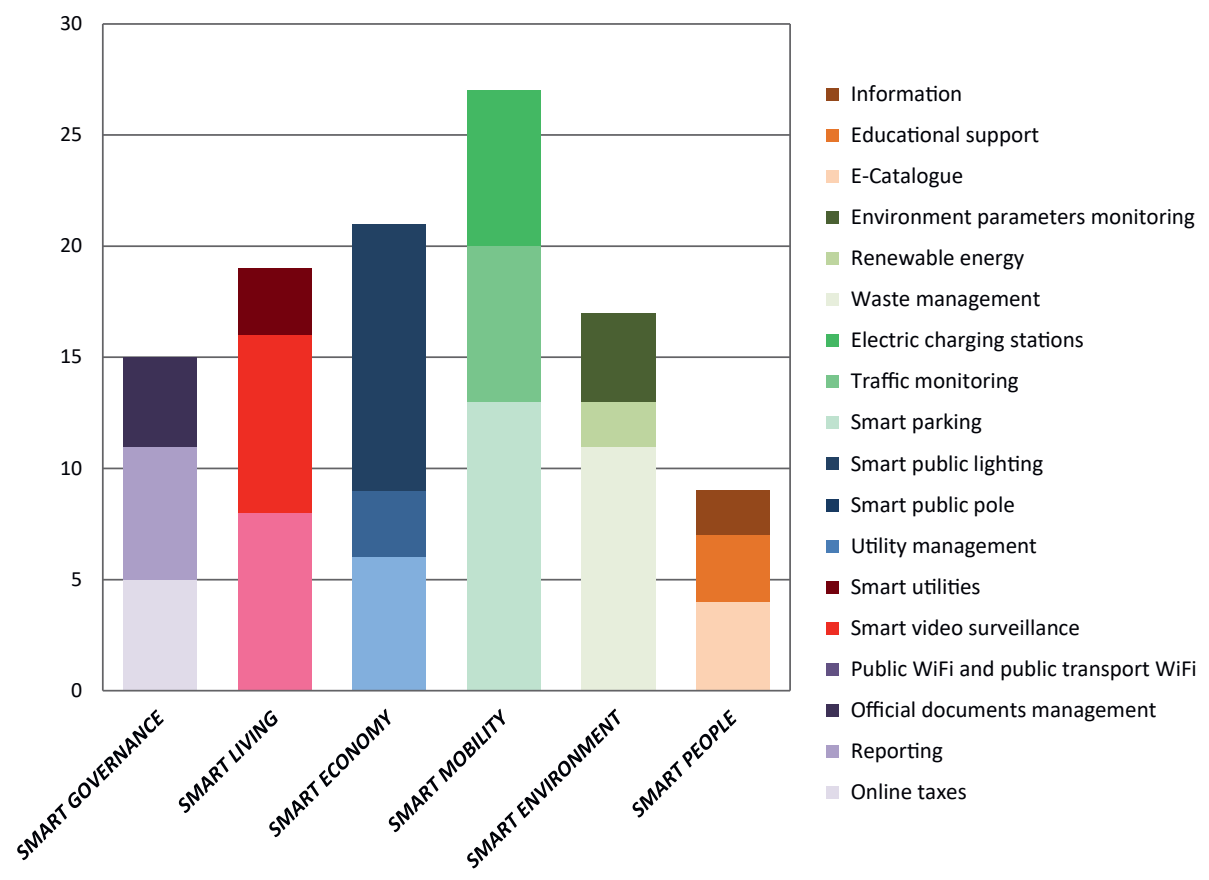

Fig. 1 - Smart City Solutions in Romania by domain. Data source: VEGACOMP 2018

parking lots and payment for parking, traffic monitoring, public transport fleet monitoring, and car charging stations.

- Smart Environment solutions concern intelligent waste management, initiatives in renewable energy and monitoring of various environmental quality parameters.

- Smart People: pilot projects aiming at implementing information systems for citizen, e-catalogues for children in schools and educational support in various areas of ICT.

One can notice some important differences when comparing the smart initiatives by domain and by type of city. Even though overall, mobility projects have the highest share (24-25\% of all projects), the medium and big cities (more than 50,000 inhabitants) reported more initiatives in smart living areas and smart governance, while the smaller cities (under 50,000 inhabitants) reported more projects in smart environment and smart economy domains (Fig. 2). Furthermore, smart governance and smart people domains prevail for medium cities (50,000-200,000 inhabitants), being more citizen and community oriented, while bigger cities prefer using ICT to solve infrastructure/mobility issues and to increase life quality by improving public facilities (parking, crossroads, parks, residential areas). 
(a) No of Smart projects by city

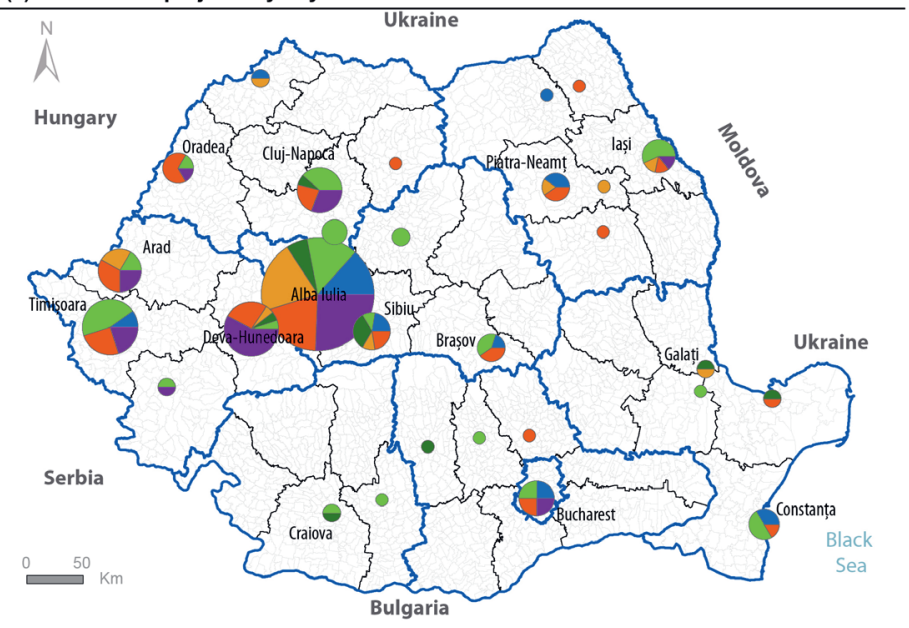

No of Smart projects (Total)

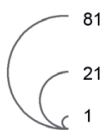

Smart Projects by Domain

S_ECONOMY

S_MOBILITY

S_ENVIRONE

S_PEOPLE

S_LIVING

S_GOVERNAN

Administrative boundries

$\square$ Regions (NUTS2) Counties (NUTS3) Communes (LAU2) (b) Smart projects by domain (all cities and towns)

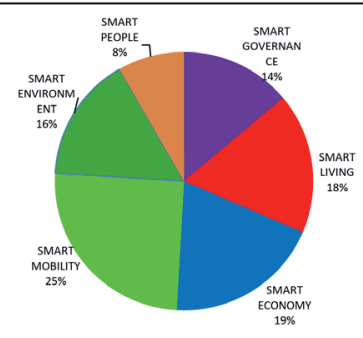

(c) Smart projects by domain (selected cities)

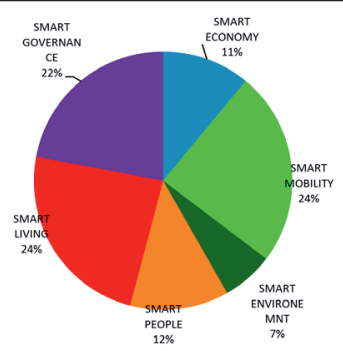

Fig. 2 - Number of Smart Projects in Romanian Cities

Figure 2 highlights several patterns of spatial distribution in smart city initiatives. Firstly, there is a clear divide between the north-western part - where most of the smart city projects are concentrated - and the rest of Romania (extra-Carpathian area), where initiatives are reduced in number, diversity and concentrated in a few cities. This divide in smart city initiatives seems to overlap the well-known development gap between richer, more accessible and more integrated Western part of Romania and the peripheral, lagging extra-Carpathian, Romanian space (Surd, Kassai, Giurgiu 2011).

Secondly, the city size seems to be an indicator (as expected) of the number of smart city initiatives, although there are notable exceptions such as Craiova, Galați and Bucharest which implemented very few smart projects compared to their size, or as Alba Iulia or Piatra Neamt, that implemented more smart city projects than expected from their population size. These two patterns suggest that smart projects are mainly the consequence of the differentiated capacity of local stakeholders to propose and implement them and allow us to affirm that more economically and 
European integrated cities offer a more suitable context for local stakeholders to mobilize for innovative projects. Finally, there are 16 cities that have only one or two smart city initiatives, mainly focused on environment, mobility and smart living. As expected, the cities having implemented more smart initiatives display a higher diversity of projects. Nevertheless, this diversity is not a consequence of an overall coherent and integrative strategy, but rather a result of different opportunities and interests. A noticeable exception is Alba Iulia, "the smartest" Romanian city that proposes a high diversity of applications and technologies to sustain urban development, and the first city in Romania to have a mid and long-term smart development strategy drafted with the World Bank (ITO 2016).

\subsection{Mapping resilience of Romanian towns and cities}

This section reports results concerning the spatial resilience capacity (SRCI), the resilience performance of Romanian cities, as well as the relationship between the two types of resilience.

\subsubsection{Resilience capacity}

Figure 3 maps the resilience capacity for the Romanian cities in 2012, at the aftermath of the economic crisis. The highest values of SRCI correspond to metropolitan areas that have already taken the regional lead (Bucharest, the capital,
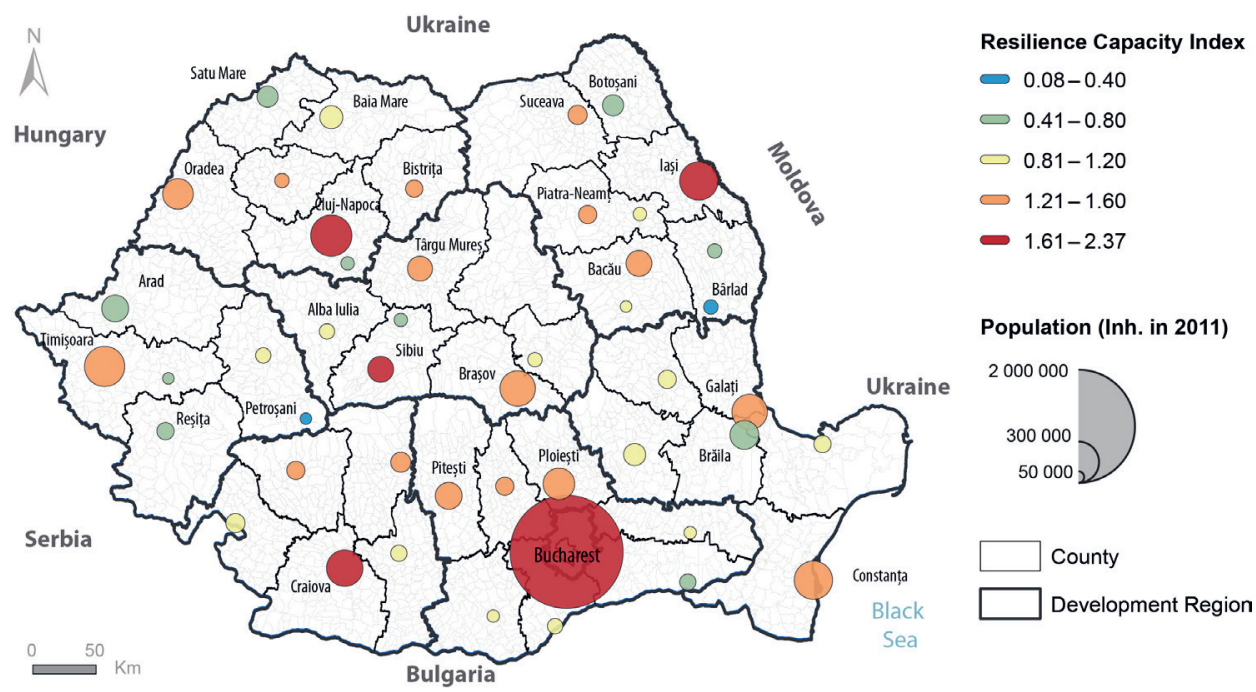

Population (Inh. in 2011)

2000000

300000

50000

County

Development Region

Fig. 3 - Spatial resilience capacity index of Romanian cities (2013) 
but also Cluj-Napoca, Timișoara, Brașov, Constanța or Iași) as they represent the development poles benefiting from investments, innovation, diversified economy, finances, high skilled human resources, infrastructure etc. and are able to adapt smoothly to present globalized challenges (Bănică, Muntele 2015). On the contrary, lowest values are recorded by cities that progressively eroded their capacities during the post-socialist deindustrialization process (Reșița, Petroșani, Botoșani, Vaslui, Bârlad).

\subsubsection{Resilience performance}

Regarding the resilience performance to the economic crisis, it was assessed by taking into consideration the evolution of total employment during and after the crisis, according to the methodology developed by Martin (2012; see section 2 Methodology).

Figure 4 displays the typology of medium and big cities according to their performance during the crisis (resistance) and in the aftermath of it (recovery). The first class, including best performing cities both during and after the crisis, includes metropolitan areas situated in central and southern part of Romania, including Bucharest and Cluj-Napoca, while it is almost absent from the Eastern part of Romania (Piatra Neamț is the only exception from North-East region). The second class includes cities that were more affected by the crisis in the first phase (less resistant), but managed to recover better than the others. Generally, it includes medium sized cities, excepting Brașov, more frequently situated in Central, Western and North Western regions. The third class includes cities that were more resistant to the crisis than the others, but less capable to recover in the
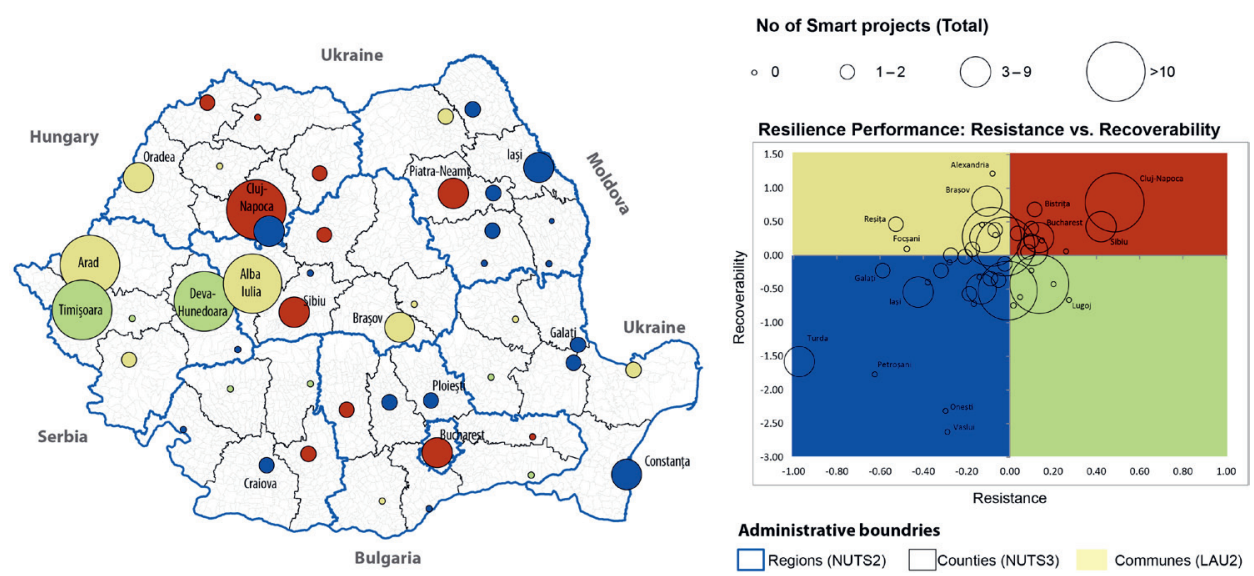

Fig. 4 - Resilience performance: resistance and recoverability of Romanian cities 
aftermath of it. They are not very numerous and include mainly medium-sized metropolitan areas (the contra-intuitive exception is Timișoara's metropolitan area, which will be approached later in the article). Finally, the less resilient cities (poor resistance, poor recovery) are concentrated in the North Eastern region. It is also important to notice that 3 big regional metropolitan areas are included in this class (Craiova, Constanța and Iași).

These results suggest several interesting aspects related to the literature. Firstly, city size does not seem to play an important role in explaining the different behavior in the economic crisis, as medium and big cities are almost equally distributed among the four categories. Secondly, cities situated in poorer, less economically integrated areas (for example, in the North-Eastern region) were the most affected by the crisis, recording low performance on both resistance and recovery. Finally, the cases of Cluj-Napoca and Timișoara seem to confirm the existing theories in resilience which sustain that endogenously developed economies are more resilient than others (Hudson 2010). These two cities are quite similar in rank and size, both being situated in the western, more developed, part of Romania. Nevertheless, while local economy of Cluj-Napoca is mainly defined by the high density of small and medium size enterprises, Timișoara is well known for its early foreign direct investments and the headquarters of several important multi-national companies. Hence, the better performance of Cluj-Napoca can be interpreted as a consequence of the more dynamic local entrepreneurial ecosystem (Huggins, Thompson 2015; Williams, Vorley 2014).

In order to better understand the urban resilience and the connections between different facets of it, as well as to secure an improved comprehension of previous results, we proceeded to the analysis of the relation between resilience capacity and resilience performance. Furthermore, for a better assessment, we introduced one complementary measure of resilience performance: the share of employment in secondary and tertiary sectors, both during and in the aftermath of the crisis. These indicators allowed us to spot the structural changes occurred during the crisis, which are more relevant for measuring the adaptive or evolutionary resilience.

The correlation matrix employed to assess the relationship between resilience capacity and resilience performance is presented in Table 3 . The resistance index displays significant positive correlation to the resilience capacity index, as well as to its social and economic component. Meanwhile the recovery index is more intensely correlated to the social resilience capacity component. Recovery index is negatively correlated with the industrial employment, thus enhancing the relevance of social factors in explaining resilience as well as the relevance of tertiary employment dynamics as a measure of resilience performance.

There is no significant association between the evolution of industrial employment during the two phases (IND\%08-11 and IND\%11-16) and spatial resilience capacity (SRCI). The same result holds for the relationship between the evolution 
Table 3 - Correlation matrix

\begin{tabular}{|c|c|c|c|c|c|c|c|c|c|c|}
\hline $\mathrm{SRCl}$ & 1 & & & & & & & & & \\
\hline Econ_Res & 0.897 & 1 & & & & & & & & \\
\hline SD_Res & 0.867 & 0.642 & 1 & & & & & & & \\
\hline EC_Res & 0.261 & 0.187 & -0.117 & 1 & & & & & & \\
\hline Resist Index & 0.421 & 0.313 & 0.395 & 0.172 & 1 & & & & & \\
\hline Recov index & 0.374 & 0.241 & 0.420 & 0.054 & 0.434 & 1 & & & & \\
\hline IND\%08-11 & -0.022 & -0.140 & 0.110 & -0.093 & 0.167 & 0.043 & 1 & & & \\
\hline IND\%11-16 & -0.076 & -0.077 & -0.160 & 0.225 & -0.192 & -0.269 & 0.183 & 1 & & \\
\hline SERV\%08-11 & 0.206 & 0.250 & 0.150 & 0.000 & 0.356 & 0.075 & 0.195 & -0.185 & 1 & \\
\hline \multirow[t]{2}{*}{ SERV\%11-16 } & 0.539 & 0.319 & 0.672 & -0.029 & 0.279 & 0.213 & 0.095 & -0.057 & 0.137 & 1 \\
\hline & SRCl & Econ_Res & SD_Res & EC_Res & Resist Index & Recov index & IND\%08-11 & IND\%11-16 & SERV\%08-11 & SERV\% $11-16$ \\
\hline
\end{tabular}

SRCI - Spatial Resilience Capacity Index

Econ_Res - Economic resilience

SD_Res - Social-demographic resilience

EC_Res - Environmental and community resilience

Resist Index - Resistance Index

Recov index - Recovery Index

IND\%08-11 - Evolution of employment in secondary sector (2008-2011)

IND\%11-16 - Evolution of employment in secondary sector (2011-2016)

SERV\%08-11 - Evolution of employment in tertiary sector (2008-2011)

SERV\%11-16 - Evolution of employment in tertiary sector (2011-2016)

of industrial employment and each of the three domains of resilience capacity (Econ_Res, SD_Res, EC_Res). On the contrary, there is a strong and significant association between the evolution of tertiary employment after crisis (SERV\%11-16) and spatial resilience capacity (SRCI) which suggests that cities with higher resilience capacity also displayed a more intense restructuring to tertiary sector. It seems that most of the association is due to the Economic resilience (Econ_Res) and the Social-demographic resilience (SD_Res), the latest being the best predictor of the evolution of tertiary employment $(r=0.6)$, while the Environmental and community resilience (EC_Res) is not significantly correlated. Our findings sustain the results documented in the literature on post-socialist cities in Central and Eastern Europe, which suggest that increasing the level of economic and socialdemographic resilience (increasing the level of education attainment, the access to health care, along with increasing incomes and the out of poverty rate) could foster structural changes to tertiarization (Kreja 2004; Garb, Dybicz 2006; Jakovcic 2008; Sandu 2019).

Given the intensity of the relation between resilience performance (measured as tertiary sector dynamics - SERV\%11-16) and the Social-demographic resilience (SD_Res), we chose to further explore the spatial patterns of this relation through the map presented in Figure 5. The color selection indicates the deviation of selected cities towards the employment in tertiary sector (brown, red), or towards 

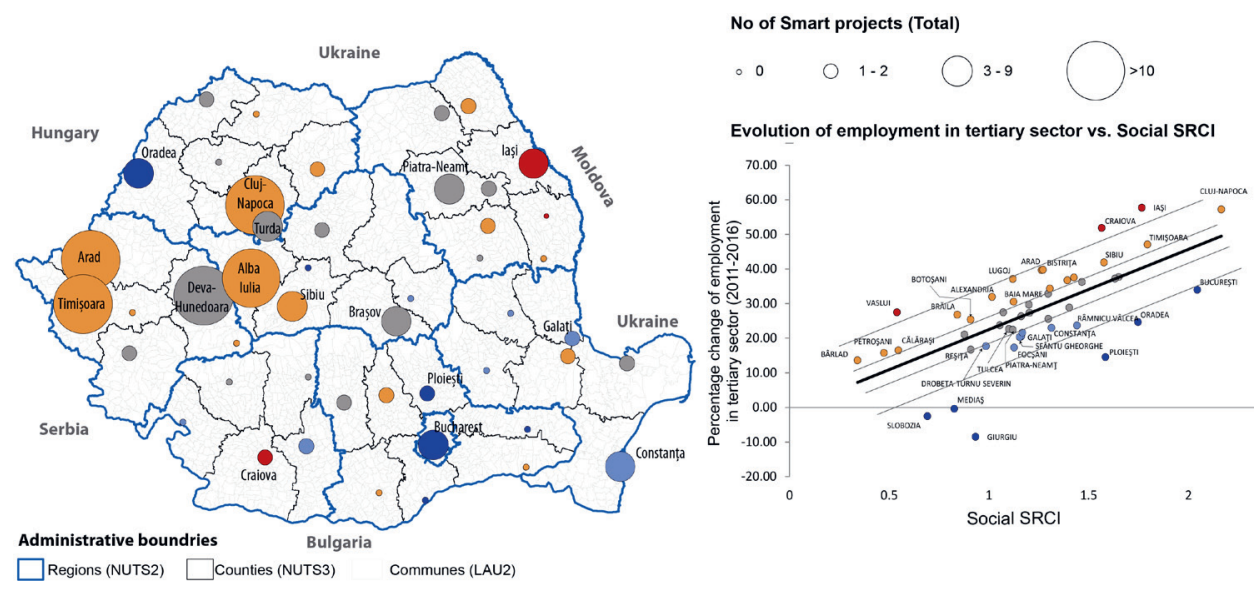

Fig. 5 - Evolution of employment in tertiary sector (2011-2016) vs Social-demographic resilience

social-demographic resilience (blue). An evident concentration of cities with deviation towards social-demographic resilience can be observed in the southern part of the country.

With regard to the number of smart initiatives, it can be observed a clear deviation of "smarter" cities towards employment in the tertiary sector. Within the selected cities that invested in smart projects, there are two dominant categories: cities with high social resilience that also have a more obvious transformation towards tertiarisation (Cluj-Napoca, Bucharest, Alba Iulia, Timișoara, Iași, Brașov) and cities that, even though they underwent similar transformations, they still have a comparatively lower (but increasing) social resilience capacity (Arad, DevaHunedoara, Piatra Neamț).

\subsection{Exploring the statistical relationship between smart city initiatives and resilience}

This section focuses on the links between smart city initiatives and urban resilience in Romanian medium and big cities. The issue has not, to our knowledge, been explored in a quantitative manner yet. We investigated this relation in two steps that correspond to the main hypotheses raised by this research. Firstly, we looked at the statistical correlation between Spatial Resilience Capacity Index (SRCI), calculated for 2013, and the number of smart city initiatives afterwards. Then we looked at the statistical relationship between resilience performance during the crisis (2008-2011) and the number of smart city initiatives, as well as at the correlation between outcome resilience during the bounce-back period (2011-2016) and the number of smart city initiatives. 


\subsubsection{Smart city initiatives vs. Spatial Resilience Capacity Index}

The first hypothesis, related to the positive statistical relationship between resilience capacity and smart city initiatives, is validated to a significant extend by the results outlined in Table 4 and Figure 6. Pearson correlation coefficients show that the Spatial Resilience Capacity Index (and especially its social-demographic dimension) significantly explains some of the variation in the number of smart projects initiatives (Table 4). The lack of any significant correlation in the case of economic and environmental components of the resilience capacity could also be explained by very poor data concerning the number of smart city initiatives, as well as by the fact that Romanian cities are still in an incipient phase towards implementing smart projects.

Certain patterns can be identified from a territorial perspective (Fig. 6). Overall, Romanian cities displaying a higher resilience capacity did implement more smart projects (red colour on the map), while the least resilient ones implemented a limited number of smart projects (blue colour on the map). The high number of red and blue coloured cities on our visual representation seems to sustain the overall pattern.

Nevertheless, there are also intriguing examples of resilient cities with few smart projects (mango colour) or less resilient cities with relatively numerous smart projects (lemongrass colour). The former category includes only three cities that recorded a below average resilience capacity in 2013, but performed rather well in implementing smart projects (Deva-Hunedoara, Arad and Turda). They are all situated in the western part of Romania (North-Western and Western regions), in the proximity of cities that were both resilient and oriented towards smart city projects (Cluj Napoca, Timișoara, Alba Iulia). This territorial pattern suggests that
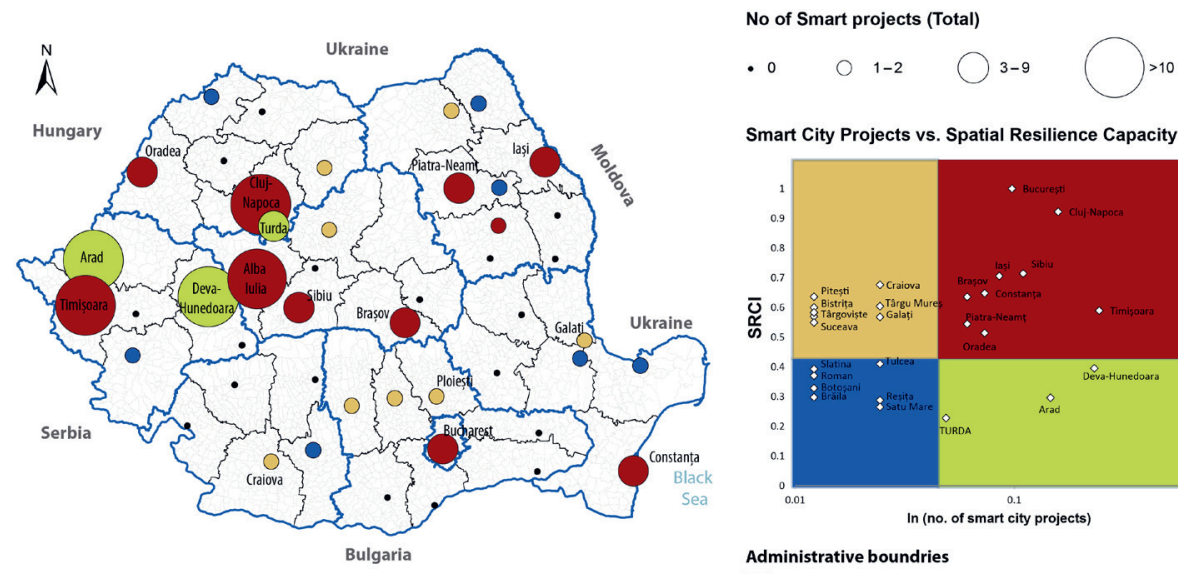

Smart City Projects vs. Spatial Resilience Capacity Index

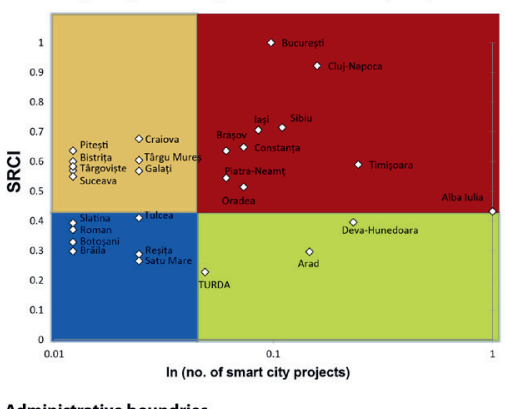

$\square$ Regions (NUTS2) $\square$ Counties (NUTS3) Communes (LAU2)

Fig. 6 - Smart City Projects and Spatial Resilience Capacity Index 
Table 4 - Pearson correlation coefficients (number of smart projects against different measures of urban resilience capacity)

\begin{tabular}{lc}
\hline Variables related to urban resilience & Sqrt (No. of smart projects) \\
\hline Spatial Resilience Capacity Index (standardised) & $0.305^{* *}$ \\
Economic resilience (standardised) & 0.189 \\
Social-demographic resilience (standardised) & $0.475^{* *}$ \\
Environmental and community resilience (standardised) & -0.268 \\
\hline
\end{tabular}

${ }^{* *} p<0.05$

spatial spill over effects in implementing smart city projects may exist. On the other hand, there are 8 cities that recorded above average resilience capacity in 2013 but have not taken steps toward implementing smart city initiatives (Craiova, Pitești, Târgu Mureș - mango colour). All these cities (exept for Târgu Mureș and Bistrița), are located in the extra-Carpathian space.

\subsubsection{Smart city initiatives vs. resilience performance}

The second hypothesis concerns the statistical relationship between the resilience performance and the number of smart city initiatives. Resilience performance has been assessed by computing Ron Martin's Resilience Performance Index on the number of employees in secondary (industry) and tertiary (services) sectors during both the resistance (2008-2011) and the recoverability periods (2011-2016). Furthermore, percentage change in employment by sector and by period have been computed and tested against the number of smart city projects initiatives.

During the resistance period (2008-2011), all cities display a general decrease in the number of employees in industry, along with only a small increase in services (Fig. 7). However, following the year 2011, the "low-tech" industrial sector underwent a revival, especially in cities that were not interested at all in innovative smart projects. Employment in services reported higher fluctuations during the recovery period, especially in cities which implemented smart projects. No major differences in employment variations between "smartest" cities" and the rest seems to emerge at first glance. However, some interesting patterns emerge when taking a closer look at the correlation between the recoverability / resistance after the crisis and the number of implemented smart projects. (Fig. 8).

The most resistant cities during crisis were also those which chose the "smart path" afterwards (>10 smart projects per city). They underwent deep transformations during the crisis, and the after-crisis recovery meant a transition not only to a smarter model, but also to another urban functional structure. By contrary, cities that did not follow the "smart path" were among the least resistant and kept their development pattern, being locked-in a pre-set trajectory, without the chance 


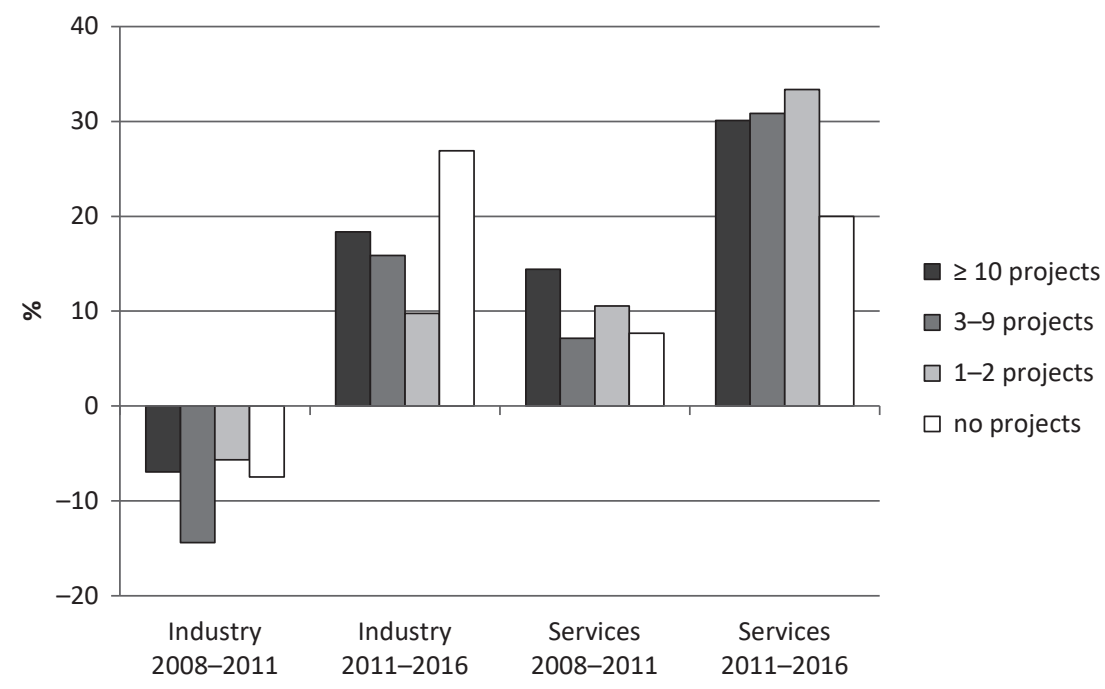

Fig. 7 - Recent dynamics of employment in industry and services in relation to the number of implemented smart city projects

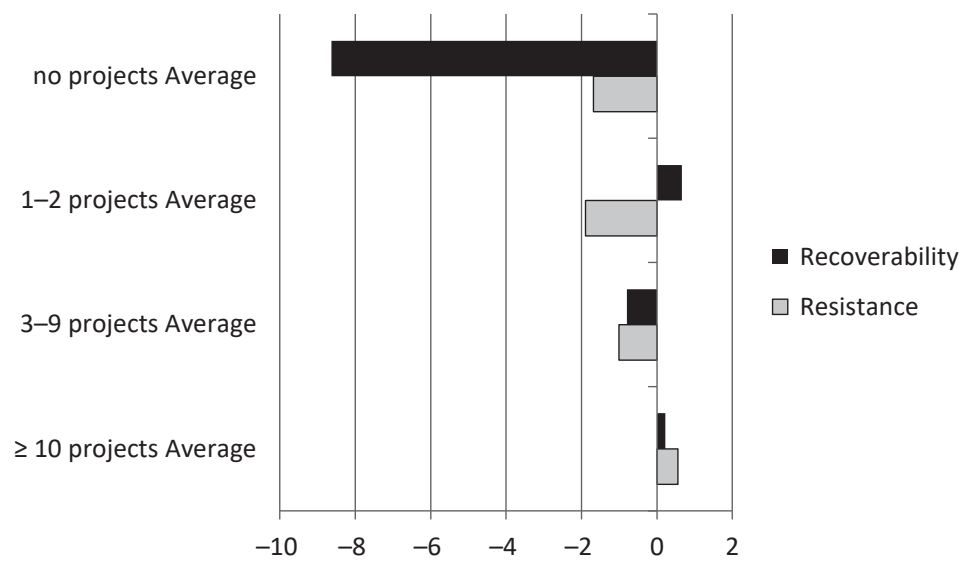

Fig. 8 - Recoverability and resistance (regarding employment rate) after the 2008 crisis in relation to the number of implemented smart city projects

(and/or the resources) to innovate or to use other opportunities. Furthermore, those cities that did not implement smart projects proved to be by far the least resilient during the recovery period.

From a territorial perspective, the results show that cities tend to cluster based on their number of smart initiatives and their resilience performance index during recoverability period (Fig. 9): the cities which are both the most resilient and the 

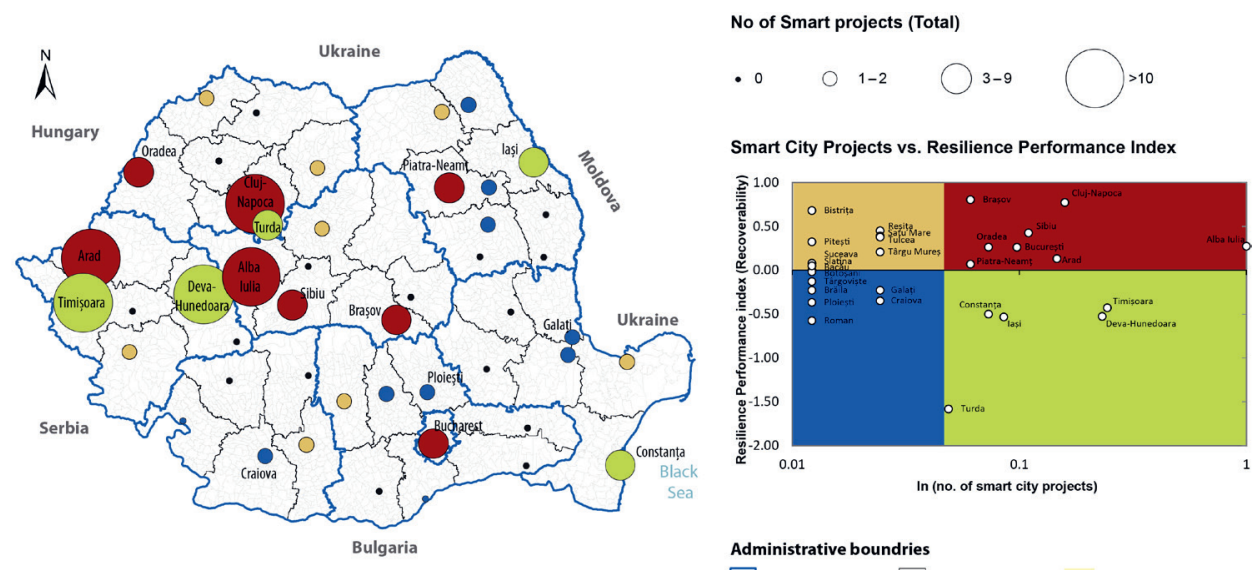

$\square$ Regions (NUTS2) $\square$ Counties (NUTS3) Communes (LAU2)

Fig. 9 - Smart City Projects vs Resilience performance index (Recoverability)

most dynamic in implementing smart initiatives are to be found in Transylvania, whilst the ones that are both the least resilient and that have implement the lowest number of smart projects are to be found, without exception, in the extraCarpathian space (Moldavia and Valachia).

\section{Conclusions}

The present paper first inquired the geography of urban resilience and city "smartness" in Romania. It then analysed the statistical relationship between three different components of urban resilience and the number of smart city initiatives. The authors investigated, on the one hand, if cities displaying a high resilience capacity were also more involved in implementing smart city projects and, on the other hand, whether the urban areas which performed better in recovering from the latest economic crisis were also more likely to develop and implement smart city projects. A multifaced concept hard to operationalize, the resilience was assessed from two perspectives: resilience capacity (adapting RCI to Romanian realities - SRCI) and resilience performance (using Ron Martin's model) divided in resistance to economic crisis and recoverability after the crisis. Both perspectives on resilience have given complex pictures on the potential of cities to resist, adapt and transform after the crisis.

Our first hypothesis, related to the statistically positive relationship between resilience capacity and smart city initiatives, was validated only to a very limited extent. The second hypothesis, related to the relationship between resilience performance and smart city initiatives, was validated to a higher extent, as most of the 
cities that had a good recoverability after the crisis also invested in technological innovation or smart projects. The findings pinpoint at social-demographic resilience capacity and at the accelerated tertiarisation of cities as significant drivers of the transition towards smart cities in Romania. After the economic crisis, the social vectors were fundamental in conducting cities towards a new regeneration phase of adaptive cycle, by sustaining smart initiatives. The cities that had suffered the most severe impact of crisis have also invested the most, afterwards, in smart initiatives, succeeding in bouncing back and adapting to the new context. By contrary, the cities that were the most resistant seem to remain locked-in their former development path, to maintain their industrial profile and did not make many (or any) steps towards investing in smart initiatives.

The findings present practical use for urban policy makers in their quest for urban "smartness" and resilience building. As the application of the smart city concept in Romania is rather recent and the current smart initiatives have integrated to a lesser extent the economic and environmental domains, focusing more on infrastructure and social amenities, it is too early to assess the long-term efficiency of smart initiatives from the point of view of urban resilience. Nevertheless, the preliminary results of this study suggest the importance of better adapting the smart urban innovation according to the local conditions in order to grant more coherency and effectiveness in sustaining urban resilience.

\section{References}

AHERN, J. (2011): From fail-safe to safe-to-fail: Sustainability and resilience in the new urban world. Landscape and Urban Planning 100, 341-343.

AHUJA, A. (2016): Integration of nature and technology for smart cities. Springer International Publishing, Chicago.

ALBINO, V., BERARDI, U., DANGELICO, R.M. (2015): Smart cities: definitions, dimensions, performance and initiatives. Journal of Urban Technology, 22, 1, 3-21.

BĂNICĂ, A., ISTRATE, M., MUNTELE, I. (2017): Challenges for the Resilience Capacity of Romanian Shrinking Cities. Sustainability, 9, 12, 2289.

BĂNICĂ, A., MUNTELE, I. (2015): Teritoriu si rezilienta. Terra Nostra, Iasi.

BĂNICĂ, A., MUNTELE, I. (2013): Romanian functional urban areas. Between polarization and spatial resilience, http://resilient-cities.iclei.org/fileadmin/sites/resilient-cities/files/ Images_and_logos/Resilience_Resource_Point/RC2013_Banica_Muntele_01.pdf (04.05.2019).

BĂNICĂ, A., MUNTELE, I. (2017): Urban transitions and resilience of Eastern European Union cities. Eastern Journal of European Studies, 8, 2, 45-69.

BATAGAN, L. (2012): The use of intelligent solutions in Romanian cities. Informatica Economica, $16,4,37$.

BAYCAN, T., FUSCO GIRARD, L., NIJKAMP, P. (2011): Creative and sustainable cities: A new perspective. In sustainable city and creativity, promoting creative urban initiatives. Burlington: Ashgate Publishing Limited. 
BORSEKOVA, K., NIJKAMP, P. (2018): Smart cities: A challenge to research and policy analysis. Cities, 78, 1-3.

BOŞTENARU DAN, M., ARMAS, I., GORETTI, A. (eds., 2014): Earthquake hazard impact and urban planning. Springer.

BRISTOW, G., HEALY, A. (2018): Innovation and regional economic resilience: an exploratory analysis. The Annals of Regional Science, 60, 265-284.

CARAGLIU, A., DEL BO, C.F. (2019): Smart innovative cities: The impact of smart city policies on urban innovation. Technological Forecasting and Social Change, 142, 373-383.

CARAGLIU, A., DEL BO, C., NIJKAMP, P. (2011): Smart cities in Europe. Journal of urban technology, 18, 2, 65-82.

COCCHIA, A. (2014): Smart and digital city: A systematic literature review. In: Dameri, R.P., Rosenthal-Sabroux, C. (eds.): Smart city: how to create public and economic value with high technology in urban space, Springer, Cham, 13-43.

DROBNIAK, A. (2014): Factors determining urban resilience. In: Drobniak, A. (ed.): Urban resilience concept and post-industrial cities in Europe, Helion, Gliwice.

FALCO, G.J. (2015): City resilience through data analytics: a human-centric approach. Procedia Engineering, 118, 1008-1014.

FINGLETON, B., GARRETSEN, H., MARTIN, R. (2012): Recessionary shocks and regional employment: evidence on the resilience of U.K. regions. Journal of Regional Science, 52, 1, 109-133.

FOSTER, K.A. (2011): Resilience Capacity Index. Data, maps and findings from original quantitative research on the resilience capacity of 361 U.S. metropolitan regions, http://brr.berkeley. edu/rci (04.01.2019).

GALDERISI, A. (2018): Smart, resilient and transition cities: emerging approaches and tools for a climate-sensitive urban development (1st edition). Elsevier, Cambridge.

GARB, Y., DYBICZ, T. (2006): The retail revolution in post-socialist central Europe and its lessons. In: Tsenkova S., Nedović-Budić Z. (eds.): The Urban Mosaic of Post-Socialist Europe: Space, Institutions and Policy. Physica-Verl, Heidelberg, 231-252.

HOLLANDS, R.G. (2008): Will the real smart city please stand up?. City, 12, 3, 303-320.

HUDSON, R. (2010): Resilient regions in an uncertain world: wishful thinking or a practical reality? Cambridge Journal of Regions, Economy and Society, 3, 1, 11-25.

HUGGINS, R., THOMPSON, P. (2015): Local entrepreneurial resilience and culture: the role of social values in fostering economic recovery. Cambridge Journal of Regions, Economy and Society, 8, 2, 313-330.

ITO (2016): Smart Cities Regions and Communities Export Opportunities, Volume I, International Trade Organisation (ITO), Department of Commerce USA.

JAKOVCIC, M. (2008): New spaces of consumption in post-socialist city - example of the city of Zagreb, Croatia, https://bib.irb.hr/datoteka/403403.P12-Martina_Jakovcic.pdf (14.02.2019).

KOLA-BEZKA, M., CZUPICH, M., IGNASIAK-SZULC, A. (2016): Smart cities in Central and Eastern Europe: viable future or unfulfilled dream? Journal of International Studies, 9, 1, 76-87.

KOLLAR, M., BUBBICO, R.L., ARSALIDES, N. (2018): Smart Cities, Smart Investment in Central, Eastern and South-Eastern Europe, European Investment Bank (EIB). Economics Department Report.

KOMNINOS, N., KAKDERI, C., PANORI, A., TSARCHOPOULOS, P. (2018): Smart city planning from an evolutionary perspective. Journal of Urban Technology, 26, 2, 3-20. 
KOURTIT, K., NIJKAMP, P. (2012): Smart cities in the innovation age. Innovation: The European Journal of Social Science Research, 25, 2, 93-95.

KOURTIT, K. (2019): Cultural heritage, smart cities and digital data analytics. Eastern Journal of European Studies 10, 1, 151-159.

KREJA, K. (2004): Changes in spatial patterns of urban consumption in post-socialist cities: new large-scale retail development in Warsaw, https://pdfs.semanticscholar.org/292b/57b 362c96f232b1c2f26426222cf2084e4fo.pdf (04.05.2019).

LI, K., CHEN, Y., LUNA-REYES, L.F. (2017): City resilience as a framework to understand Smart cities: dimensions and measurement. In: Hinnant, C., Ojo, A. (eds.): Proceedings of the 18th Annual International Conference on Digital Government Research, DG.O 2017, Staten Island, New York, 568-569.

LOMBARDI, P., GIORDANO, S., FAROUH H., YOUSEF W. (2012): Modelling the smart city performance, Innovation: The European Journal of Social Science Research, 25, 2, 137-149.

MARTIN, R. (2012): Regional economic resilience, hysteresis and recessionary shocks. Journal of Economic Geography, 12, 1, 1-32.

MARTIN, R., SUNLEY, P., GARDINER, B., TYLER, P. (2016): How Regions React to Recessions: Resilience and the Role of Economic Structure. Regional Studies, 50, 4, 561-585.

MEEROW, S., NEWELL, J.P., STULTS, M. (2016): Defining urban resilience: a review. Landscape and Urban Planning, 147, 38-49.

MONZON, A. (2015): Smart cities concept and challenges: bases for the assessment of smart city projects. In: Helfert, M., Krempels, K.H., Klein, C., Donellan, B., Guiskhin, O. (eds.): Smart Cities, Green Technologies and Intelligent Transport Systems, Springer International Publishing, Lisbon, 579, 17-31.

NUNES, D.M., TOME, A., PINHEIRO, M.D. (2019): Urban-centric resilience in search of theoretical stabilisation? A phased thematic and conceptual review. Journal of Environmental Management, 230, 282-292.

ÖSTH, J., REGGIANI, A., NIJKAMP, P. (2018): Resilience and accessibility of Swedish and Dutch municipalities. Transportation, 45, 4, 1051-1073.

PAPA, R., GALDERISI, A., VIGO MAJELLO, M.C., SARETTA, E. (2015): Smart and resilient cities. A Systemic approach for developing cross-sectoral strategies in the face of climate change. TeMA - Journal of Land Use, Mobility and Environment, 8, 1, 19-49.

PENDALL, R., FOSTER, K., COWELL, M. (2010): Resilience and Regions: Building Understanding of the metaphor, Cambridge Journal of Regions, Economy and Society, 3, 1, 71-84.

PICKETT, S.T.A., CADENASSO, M.L., GROVE, J.M. (2004): Resilient cities: Meaning, models, and metaphor for integrating the ecological, socio-economic, and planning realms. Landscape and Urban Planning, 69, 4, 369-384.

PUENTES, R., TOMER, A. (2014): Getting smarter about smart cities. Brookings Institution, http://www.brookings.edu/research/papers/2014/04/23-smart-cities-puentes-tomer (15.03.2019).

ROMÃO, J., KOURTIT, K., NEUTS, B., NIJKAMP, P. (2018): The smart city as a common place for tourists and residents: a structural analysis of the determinants of urban attractiveness. Cities, 78, 67-75.

ROTUNA, C., CÎRNU, C.E., SMADA, D., GHEORGHIȚĂ, A. (2017): Smart city applications built on big data technologies and secure IoT, Ecoforum, 6, 3, 1-9.

RUFAT, S. (2012): Existe-t-il une «mauvaise» résilience?. In: Djament-Tran, G., Reghezza, M. (eds.): La résilience urbaine. Les villes face aux catastrophes, Editions Le Manuscrit, Paris, 195-241. 
SANDU, A. (2019): Les dynamiques urbaines post-socialistes en Europe centrale et orientale. Continuités et discontinuités dans l'évolution morphologique et fonctionnelle. Géographie. Université Lumière Lyon 2; Université Alexandru Ioan Cuza de Iasi (Roumanie).

SEDITA, S.R., DE NONI, I., PILOTTI, L. (2017): Out of the crisis: an empirical investigation of place-specific determinants of economic resilience. European Planning Studies, 25, 2, 155-180.

SHARIFI, A., YAMAGATA, Y. (2017): Towards an integrated approach to urban resilience assessment. APN Science Bulletin, 7, 1.

SIKORA-FERNANDEZ, D. (2018): Smarter cities in post-socialist country: example of Poland. Cities, 78, 52-59.

SURD, V., KASSAI, I., GIURGIU, L. (2011): Romania disparities in regional development. Procedia-Social and Behavioral Sciences, 19, 21-30.

TAYLOR BUCK, N., WHILE, A. (2017): Competitive urbanism and the limits to smart city innovation: The UK future cities initiative. Urban Studies, 54, 2, 501-519.

THOMPSON, E.M. (2016): What makes a city "smart"? International Journal of Architectural Computing, 14, 4, 358-371.

VAIDYANATHAN, N. (2016): Smarter cities, simpler cities. Accounting for the city of the future. Spotlight on India. The Association of Chartered Certified Accountants, https://www.accaglobal.com/content/dam/ACCA_Global/Technical/Future/pi-smarter-cities-simpler-cities. pdf (16.03.2019).

VEGACOMP (2018): Scanning Smart Cities Romania, First report, March 2018, Innovate networks. Re-design business, Vegacomp Consulting, https://vegacomp.ro/wpr/wp-content/ uploads/2018/10/radiografia-smart-city-romania_2018.03.20-en.pdf (16.03.2019).

VIITANEN, J., KINGSTON, R. (2014): Smart cities and green Growth: outsourcing democratic and environmental resilience to the global technology sector. Environment and Planning A: Economy and Space, 46, 4, 803-819.

WILLIAMS, N., VORLEY, T. (2014): Economic resilience and entrepreneurship: lessons from the Sheffield City Region. Entrepreneurship \& Regional Development, 26, 257-281.

\section{ACKNOWLEDGMENTS}

This work was supported by a grant of Ministery of Research and Innovation, CNCS - UEFISCDI, project number PN-III-P4-ID-PCCF-2016-0166, within PNCDI III" project ReGrowEU - Advancing ground-breaking research in regional growth and development theories, through a resilience approach: towards a convergent, balanced and sustainable European Union. 


\section{ORCID}

ALEXANDRU BĂNICĂ

https://orcid.org/0000-0001-7781-342X

MIHAIL EVA

https://orcid.org/0000-0001-6179-4578

EMA CORODESCU-ROȘCA

https://orcid.org/0000-0001-5156-5093

BOGDAN-CONSTANTIN IBĂNESCU

https://orcid.org/0000-0002-3861-2251

ANA-MARIA OPRIA

https://orcid.org/0000-0002-1055-8310

GABRIELA CARMEN PASCARIU

https://orcid.org/0000-0002-8169-0124 